\title{
Reference Ranges for Serum Biochemical Parameters among Healthy Cameroonians to Support HIV Vaccine and Related Clinical Trials
} \author{
and T. Asonganyi ${ }^{1}$ \\ ${ }^{1}$ Faculty of Medicine and Biomedical Sciences, University of Yaounde, Cameroon \\ ${ }^{2}$ Faculty of Sciences University of Yaounde, Cameroon \\ ${ }^{3}$ Salem Hospital, Salem, MA, USA
}

G.A. Alemnji*, ${ }^{, 1}$ J. Mbuagbaw ${ }^{1}$, G. Teto ${ }^{2}$, S. Nkengafac ${ }^{2}$, E. Folefac ${ }^{3}$, N. Atems ${ }^{1}$, B. Kwingwah ${ }^{1}$

\begin{abstract}
A valid scientific evaluation of the efficacy of human immunodeficiency virus (HIV) vaccines or antiretroviral drugs (ARV) includes measurement of changes in physiological parameters of subjects from known established baseline reference ranges. This study was designed to establish reference ranges for biochemical parameters among healthy adult Cameroonians to support planned HIV vaccine clinical trials and scaling up of ARV among AIDS patients. After informed consent, blood and urine samples were collected from a total of 576 adult Cameroonians and analyzed for the presence of underlying pathologies that may affect biochemical parameters. Samples from 501 of them were found eligible for the determination of reference biochemical parameters. After complete assay, the data were subjected to both parametric and non parametric statistics for analyses, with 2.5 and 97.5 percentiles considered as the lower and upper limits of reference ranges. There were $331(66.1 \%)$ males and $170(33.9 \%)$ females, with $359(71.7 \%)$ and $142(28.3 \%)$ of them residing in the urban and rural areas respectively. The ranges for biochemical parameters got were: SGOT: 8.7 - 40.7 IU/l ; SGPT: 5.2 - 29.1 IU/l ; Alkaline Phosphatase: 52.6 - $251.1 \mathrm{IU} / \mathrm{l}$; Creatinine: 0.2 - $2.2 \mathrm{mg} / \mathrm{dl}$; Total Protein : 46.9 107.4 g/l; Albumin : 30.1 - 65.2 g/l; Triglyceride : 0.1 - 3.5 g/l; HDL Cholesterol : 54.5 - 172.0 mg/dl; LDL Cholesterol: 12 - $190 \mathrm{mg} / \mathrm{dl}$; Total Cholesterol 0.9 - $3.2 \mathrm{~g} / \mathrm{l}$; Total Bilirubin: 0.4 - $3.3 \mathrm{mg} / \mathrm{dl}$; and Direct Bilirubin : 0.1 - $1.2 \mathrm{mg} / \mathrm{dl}$. These ranges are compared to ranges presently used in various clinical laboratories in Cameroon.
\end{abstract}

Keywords: Reference biochemical ranges, healthy adult cameroonians.

\section{INTRODUCTION}

The human immunodeficiency virus (HIV) constitutes a major public health problem in Cameroon with a prevalence rate of $5.5 \%$ [1]. Furthermore, Cameroon has been identified worldwide as the country with the highest HIV heterogeneity; in fact the HIV-1 group $\mathrm{N}$ has been reported only among Cameroonians $[2,3]$. In addition, it is suspected that the virus was initially transmitted from chimpanzees to humans in Cameroon, where the emergence of the AIDS pandemic occurred [4]. Therefore, current international efforts to develop an effective and affordable preventive HIV vaccine will necessarily pay attention to Cameroon in choosing appropriate populations for clinical trials. Indeed, Cameroon is at the moment one of the African countries that is building capacity for HIV vaccine trials. It has gone into partnership with leading international organisations such as the United States based Centers for Disease Control and Prevention (CDC), the Department of Defence (DoD), and the WHO/UNAIDSAAVP in efforts to bring this initiative to fruition. Such vaccine trials require a platform for clinical evaluation of safety and efficacy. Further, since the start of antiretroviral drug

*Address correspondence to this author at the Faculty of Medicine and Biomedical Sciences, University of Yaounde 1, BP 8283, Yaounde, Cameroon; Tel: 237 77461393; E-mail:georgealemnji@yahoo.com use in Cameroon, there has been a great need for a platform for the evaluation of the efficacy of treatment efforts. This will be timely particularly at this point when the Cameroon National AIDS Control Program is scaling up antiretroviral drug treatment among AIDS patients nationwide.

This platform for scientific and clinical validation of HIV vaccines and antiretroviral drugs in Cameroon would be based on reference ranges for given parameters of clinical interest. Such reference ranges are defined as the concentration of these parameters in a group of clinically healthy persons $[5,6]$. Under normal physiological conditions, haemostatic mechanisms keep these parameters within a certain limit [6]. In healthy individuals they vary considerably in different populations $[5,7]$. In body fluids, and in the absence of diseases, they are influenced by several factors such as age, sex, dietary habits of the people, geographical location and climate $[8-14$,$] . Further, several of these parameters$ show diurnal and seasonal variations [2]. They may also change as a result of variation in techniques used by different laboratories [11, 15-17].

The parameters can also vary following pathological conditions that affect major body organs and systems that produce, secret or store them such as the liver, pancreas, kidney, bone marrow and the immune system [18-20]. Administration of drugs or vaccines for therapeutic purposes or clinical trials can also cause significant variations [2]. The 
timely measurement of these parameters is therefore absolutely necessary in the evaluation of either disease state or prognosis following therapeutic or clinical interventions.

Reference ranges for biochemical parameters are nonexistent in Cameroon where, like in many other countries of the third world, it is common practice to use reference ranges established for Western populations for interpretation of laboratory results (Table 4). There is therefore need for baseline reference laboratory ranges with which to monitor not only physiological or pathological changes following administration of various drugs and vaccines to healthy persons in Cameroon, but also disease states following infection with various pathogens. The reference ranges we have established here set the stage for the development of a framework to meet these goals.

\section{MATERIALS AND METHODS}

\section{Study Design and Population}

This was a cross sectional study that recruited participants from both urban and rural communities with diverse backgrounds. The rural participants were recruited at the Shamka Foundation health unit, located in the rural village of Ekorezok in Nkolbisson some 15 kilometres from Yaounde. This village holds a population of about 30,000 inhabitants. The staple food is mainly cassava leaves (nqwem), groundnuts and cassava itself in different forms. The area is surrounded by water and inhabitants depend on the mud-fish from these streams for supplementing their diet. Inhabitants of this locality who responded to the Foundation's health unit call for people to come for HIV/AIDS voluntary counselling and testing during the December 2006 World AIDS week, were consented and included in the study. The urban study samples were collected from the city of Yaounde. This is the capital of Cameroon. It has a population estimate of about one and a half million inhabitants. As a capital city, it hosts populations from diverse backgrounds. Participants were identified from apparently healthy people who came to donate blood at the blood transfusion unit of the University of Yaounde Teaching Hospital (CHU). All consenting participants between the ages of 18 and 59 years from both the urban and rural areas were included in the study. A lower age of 18 years was used because this is the minimum age of independent consent in Cameroon. We limited the upper age at 59 years because above this age, body physiological parameers start deviating; further, people above this age would not be good candidates for clinical trials. Epi Info 2000 version 1 program was used to calculate samples size based on an expected frequency of $50 \%$ (inbuilt), a worst acceptance of $60 \%$, a confidence interval of $95 \%$ and a $p$ value of 0.05; although a minimum sample size of 96 people each for the urban and rural areas was obtained, a total of 576 participants were selected.

\section{Laboratory Procedures}

After appropriate informed consent and a structured interview that solicited information on socio-demographic and medical history, about $10 \mathrm{ml}$ whole blood was collected from overnight fasted participants by trained phlebotomists. This was aliquoted into various blood collection tubes as follows: a portion was put into the K-EDTA tube for detec- tion of HIV, malaria parasite and hepatitis B. The remaining portion was put in sterile plain tubes and allowed to clot for $4-6 \mathrm{hrs}$ before the serum was prepared by centrifugation at $3000 \mathrm{rpm}$ for 30 minutes. The serum samples were aliquoted and stored at $-20^{\circ} \mathrm{C}$ until used for measurement of biochemical parameters. For urine collection, participants provided the samples in an appropriately labelled container given to them.

\section{Screening for Exclusion from the Study}

HIV serology was done on the 576 consenting participants using two rapid test kits, Determine (Abbott Laboratories, Abbott Park, IL, USA) and OraQuick (OraSure Technology Inc). Discordant samples were further tested using a tie-breaker, CAMSTIC (MINRESI, Yaounde). Samples that were positive with CAMSTIC were considered positive while those tested negative were considered negative. The thick blood film method was used to diagnose infection with malaria parasites; pregnancy and glucose were detected in urine by dipstick (Accurate and Medi - Test Combi 9). Hepatitis B/C surface antigen was detected by serology (Murex Abbott). Participants with the following outcomes that could affect the serum biochemical parameters were excluded from the study (75 out of the 576 initial participants): pregnancy, HIV-positive status, hepatitis $\mathrm{B} / \mathrm{C}$ infection, malaria, and urine glucose. Those diagnosed HIVpositive were orientated to Care and Treatment Centers after appropriate post test counselling and follow-up.

\section{Biochemical Estimation of Reference Ranges}

All serum biochemical parameters were assayed by spectophotometry using kits from various manufacturers as indicated:

Serum aspartate aminotransferase - ATS (Orgernon, S.A, Spain), serum alanine aminotransferase - ALT (Quimica Clinica Aplicada, S.A, Spain), alkaline phosphatise - ALP (Quimica Clinica Aplicada, S.A, Spain), total and direct bilirubin (Human, Germany), creatinine (Quimica Clinica Aplicada, S.A, Spain), total and high density lipoprotein cholesterol (Quimica Clinica Aplicada, S.A, Spain), triglycerides (Elitech, France), albumin and total protein (Human, Germany). The concentration of LDL-C was calculated using FRIEDEWALD'S formula [12].

\section{Quality Assurance/Quality Control}

To ensure the reproducibility and repeatability of the test results, all pre-analytical, analytical and post-analytical precautions were taken into consideration. For example, all Standard Operating Procedures (SOPs) were reviewed for accuracy, all guidelines for sample collection, processing, storage and handling were strictly adhered to; instruments, personnel and procedure validation were carried out through an internal quality control (QC) program in which several samples were assayed through intra and inter daily laboratory runs, with the calculation of standard deviations (SD) and coefficient of variations $(\mathrm{CV})$ before the start of the study. Daily sample runs were usually done with blinded samples whose values were known only to the quality control officer. 


\section{Statistical Analysis}

Statistical analyses were done using STATA version 9.2 (Statacorp., Texas, USA). Means and standard deviations were calculated for normally distributed continuous data. Medians and the $25^{\text {th }}$ and $75^{\text {th }}$ percentiles were computed for the laboratory parameters. To further quantify the spread of the data for each of the laboratory parameters, the $2.5^{\text {th }}$ and the $97.5^{\text {th }}$ percentiles have been presented.

\section{Ethical Approval}

The study was approved by the Ethics Committee of the Ministry of Public Health of Cameroon and the Institutional Review Board (IRB) of the Faculty of Medicine and Biomedical Sciences, University of Yaounde. All participants received a one-on-one pre-test counselling that was followed by reading and signing of consent forms for their acceptance to participate. Only those who accepted and signed the consent forms were enrolled into the study.

\section{RESULTS}

The results are depicted in the following 4 tables:

Table 1. Demographics Characteristics of Participants

\begin{tabular}{|c|c|}
\hline Characteristics $(\mathbf{N}=501)$ & Mean (SD) \\
\hline Age (years) & $27.6(8.0)$ \\
\hline Weight (kilograms) & $71.5(11.6)$ \\
\hline Height (meters) & $1.7(0.1)$ \\
\hline Sex & $\mathrm{n}(\%)$ \\
\hline Male & $331(66.1)$ \\
\hline Female & $170(33.9)$ \\
\hline Education & $\mathrm{n}(\%)$ \\
\hline $\begin{array}{l}\text { General certificate of education, advance level } \\
(\text { GCE A/L) }\end{array}$ & $135(26.9)$ \\
\hline Bachelors degree & $102(20.4)$ \\
\hline $\begin{array}{l}\text { General certificate of education, ordinary level } \\
\text { (GCE O/L) }\end{array}$ & $162(32.3)$ \\
\hline First school leaving certificate & $102(20.4)$ \\
\hline Residential areas & $\mathrm{n}(\%)$ \\
\hline Urban & $359(71.7)$ \\
\hline Rural & $142(28.3)$ \\
\hline
\end{tabular}

\section{Summary of Results}

The mean ages, weights and heights of the entire population were 27.6 years, $71.5 \mathrm{~kg}$ and 1.7 meters respectively. The males constituted $66.1 \%$ (328) while the females $33.9 \%$ (168) of the total population. Educational status of the participants was as follows: GCE A/L (26.9\%), GCE O/L
(32.3\%), First school leaving certificate $(20.4 \%)$ and Bachelors degree (20.4\%) (Table 1); $71.7 \%$ and $28.3 \%$ of them were recruited from the urban and rural areas respectively. A total of 576 participants were assessed for eligibility; 75 of them were excluded and 501 were retained for sample analyses for various biochemical parameters (Table 2). The ranges for biochemical parameters got were: SGOT: 8.7 - 40.7 IU/l; SGPT: 5.2 - 29.1 IU/l; Alkaline Phosphatase: 52.6 - 251.1 IU/l; Creatinine: 0.2 - $2.2 \mathrm{mg} / \mathrm{dl}$; Total Protein : 46.9 - 107.4 g/l; Albumin: 30.1 - $65.2 \mathrm{~g} / \mathrm{l}$; Triglyceride : 0.1 - $3.5 \mathrm{~g} / \mathrm{l}$; HDL Cholesterol : 54.5 - 172.0 mg/dl; LDL Cholesterol: 12 - 190 mg/dl; Total Cholesterol 0.9 - 3.2 g/l; Total Bilirubin: 0.4 - $3.3 \mathrm{mg} / \mathrm{dl}$; and Direct Bilirubin : 0.1 - $1.2 \mathrm{mg} / \mathrm{dl}$ (Table 3).

Table 2. Sampling

\begin{tabular}{|l|l|}
\hline Assessed for eligibility & 576 \\
\hline Excluded & 75 \\
\hline Eligible for Biochemical analysis & 501 \\
\hline Reasons for exclusion & \\
\hline Pregnancy & 11 \\
\hline HIV-positive & 36 \\
\hline Hepatitis B/C & 9 \\
\hline Malaria & 15 \\
\hline Urine glucose & 4 \\
\hline
\end{tabular}

\section{DISCUSSION AND CONCLUSION}

Reference ranges for biochemical parameters are nonexistent in Cameroon. Although "normal" ranges are used in the various Clinical Laboratories in Yaounde (Table 4) and the rest of the country, they are based on values obtained in various kits standardized on foreign populations, rather than on studies carried out on a well characterized sample of the population. Several data for "normal" controls exist for several studies, published on Cameroon populations, but the "normal subjects" were not usually controlled for confounding factors and results were not adequately analyzed and presented in a format that was strong enough to assist various clinical and laboratory scientists when confronted with problems that needed inferences to the normal population [21-24]. To overcome these challenges, a sizeable, representative population from both the urban and rural areas of Cameroon that met universally established inclusion criteria was used for the present study. The demographic data collected (Table 1) truly mirrors information that was obtained during the 2004 nationwide Demographic and Health Survey (DHS) [1], meaning that these reported reference ranges may be a true reflection of the entire adult population of urban and rural areas of Cameroon. The marked differences in our data compared to data presently used in the various laboratories (Table 4) indicates the need for further studies to reach compromises on the interpretation of biochemical data in Cameroon. In doing this, attention should be paid to the several underlying pathologies that were used as criteria for exclusion of certain participants from the study (Table 2). 
Table 3. Analysis of Overall Biochemical Parameters

\begin{tabular}{|c|c|c|c|c|}
\hline Parameter $(\mathrm{N}=501)$ & Units & Mean (SD) & Median (Q1; Q3) & $2.5^{\text {th }}, 97.5^{\text {th }}$ percentiles \\
\hline SGOT & $\mathrm{u} / \mathrm{l}$ & 19.7(7.6) & $18.2(14.0 ; 23.6)$ & $8.7-40.7$ \\
\hline Alkaline Phosphatase & $\mathrm{U} / \mathrm{L}$ & $118.5(55.8)$ & $105.4(87.4 ; 138.0)$ & $52.6-251.1$ \\
\hline Creatinine & $\mathrm{mg} / \mathrm{dl}$ & $0.7(0.6)$ & $0.6(0.4 ; 0.9)$ & $0.2-2.2$ \\
\hline Albumin & $\mathrm{g} / \mathrm{l}$ & $45.8(8.9)$ & $45.6(39.6 ; 51.0)$ & $30.1-65.2$ \\
\hline Triglyceride & $\mathrm{g} / \mathrm{l}$ & $1.1(0.9)$ & $0.9(0.6 ; 1.4)$ & $0.1-3.5$ \\
\hline HDL Cholesterol & $\mathrm{mg} / \mathrm{dl}$ & $101.9(29.3)$ & $97.0(82.0 ; 118.0)$ & $54.5-172.0$ \\
\hline LDL Cholesterol & $\mathrm{Mg} / \mathrm{dl}$ & $79.1(49.6)$ & $74.0(39 ; 110.0)$ & $12-190$ \\
\hline Direct Bilirubin & $\mathrm{mg} / \mathrm{dl}$ & $0.5(0.3)$ & $0.4(0.3 ; 0.7)$ & $0.1-1.2$ \\
\hline
\end{tabular}

Table 4. Normal Values Presently Used in Clinical Laboratories in Cameroon

\begin{tabular}{|l|l|l|l|l|l|l|l|}
\hline Parameters & Units & CHU & HGY & HGOPY & CPC & HCY & This Study \\
\hline \hline GOT & $\mathrm{UI} / \mathrm{L}$ & $\mathrm{M}:<37 ; \mathrm{F}:<31$ & $9-30$ & $9-30$ & $5-45$ & $<40$ & $8.7-40.7$ \\
\hline GPT & $\mathrm{UI} / \mathrm{L}$ & $<49$ & $8-42$ & $8-42$ & $5-50$ & $<45$ & $5.2-29.1$ \\
\hline Albumine & $\mathrm{g} / \mathrm{l}$ & $38-54$ & $35-50$ & $35-50$ & $35-50$ & $35-50$ & $30.1-65.2$ \\
\hline Total Bilirubine & $\mathrm{mg} / \mathrm{l}$ & $<10$ & $<10$ & $2-15$ & $5-14$ & $2-14$ & $0.4-3.3$ \\
\hline Direct Bilirubine & $\mathrm{mg} / 1$ & $<3$ & $<4$ & $1-5$ & $<5$ & $0-2$ & $0.1-1.2$ \\
\hline Cholestérol total & $\mathrm{g} / \mathrm{l}$ & $1.4-2.7$ & $1.4-2.7$ & $1.4-2.7$ & $1.8-2.8$ & $1.4-2.7$ & $0.9-3.2$ \\
\hline HDL Cholestérol & $\mathrm{g} / \mathrm{l}$ & $0.41-0.75$ & $0.4-0.75$ & $0.4-0.75$ & $0.3-0.9$ & $>.35$ & $0.55-1.72$ \\
\hline LDL Cholestérol & $\mathrm{g} / \mathrm{l}$ & $1-1.9$ & - & $1-1.9$ & $1-1.6$ & $1-1.5$ & $0.1-1.9$ \\
\hline Creatinine & $\mathrm{mg} / 1$ & $6-13$ & $5-15$ & $5-15$ & $5-14$ & $6-11$ & $2-22$ \\
\hline Total Proteins & $\mathrm{g} / 1$ & $68-88$ & $64-83$ & $64-83$ & $60-85$ & $65-80$ & $46.9-107.4$ \\
\hline Triglycerides & $\mathrm{g} / 1$ & $0.46-1.5$ & $0.35-1.6$ & $0.35-1.6$ & $<1.5$ & $0.4-1.7$ & 0.1 to 3.5 \\
\hline
\end{tabular}

CHU: University Hospital Center Yaounde.

HGY: General Hospital of Yaounde.

HGOPY: Yaounde Gynaeco-Obstetric and Paediatrics Hospital Yaounde.

CPC: Centre Pasteur, Yaounde.

HCY: Central Hospital, Yaounde.

Indeed, in the tropical context, there has been some disagreement in relation to the definition of a normal individual because of the fact that in this region, it would be impossible to find an individual who does not harbor at least a single parasite. In line with this, there is the need to look at the clinical pathological implications of these parasites in relation to the parameters in question. For example, an inclusion criterion for a study that seeks to establish normal or reference ranges for hematological parameters needs to target parasites that affect the hematological picture, likewise for biochemical parameters; however, inclusion of parasite density would give clinical laboratory meaning to the results obtained. We combined laboratory information with a good medical history of various participants to select individuals who were eligible for biochemical analysis.

In keeping with reports from similar studies that have been conducted in other countries, these parameters would be influenced by several factors including sex, age, diet, and geographic location [8-14]. As a quality assurance measure, all necessary pre-analytical, analytical and post-analytical precautions were taken to ensure that these data were not biased or thwarted by any factors.

The liver participates in a variety of metabolic activities such as detoxification and excretion of vaccines and drugs. Hence, any abnormal concentrations or constituents of these 
substances given to subjects will affect the liver's architecture and be presented in the serum or plasma as abnormal levels of its metabolites, such as enzymes and bilirubin, and so indicate the functional integrity of the liver [7]. Creatinine, a serum metabolic product of muscle creatine phosphate, is the principal indicator of renal function, and is usually associated with the muscles [5, 8, 13]. Serum total proteins have in general been used to assess the state of hydration and nutritional status of individuals; hence, their variations will usually reflect peoples' lifestyles and habits $[12,13]$. Serum albumin is a protein with a half life of 19 days usually used to differentiate cases of acute and chronic liver failure; it also serves an additional function as a binding and transport protein for several substances including bilirubin and hormones [25]. Several factors like diet, sex, age, and lifestyle will influence changes in serum lipid levels [8-12]. These could partly explain the significant and specific differences observed in both triglyceride and total cholesterol levels in the present study, especially with respect to the "normal" values presently used in clinical laboratories (Table 4).

A literature search shows that there have been a lot of limitations on data generated in similar studies from other African countries. For example, sample sizes have been very limited, inclusion and exclusion criteria were poorly defined, and sex and residential identities were sometimes not highlighted. A very important weakness of several of these studies has also been the statistical analyses. Several biochemical parameters, particularly the enzymes and lipids, do not show Gaussian distribution; hence skewed data from these parameters can only be analysed and presented using nonparametric statistics. This has not been the case for several studies which imply that either data were poorly collected or several acceptable variables were erroneously eliminated in order to conveniently use parametric statistics in presenting the results. The only available study with similar methodology to the present study and whose results could be compared within the African regions is that of Kayitenkore et al. [13] from Rwanda, which shows similar patterns to those of the present study, except for variabilities attributable to differences in geographic region, and underlying physiological factors. Other studies have also shown variations between reference ranges [15, 21, 25, 26].

Proposed reference ranges for biochemical parameters among healthy adult Cameroonians based on data generated from this study are presented in Table 3. There is need for further studies in a similar population and other populations likes Paediatrics, Adolescent and Geriatric populations in Cameroon to develop a consensus on the interpretation of biochemical data in Cameroon.

\section{ACKNOWLEDGEMENTS}

We are grateful to Prof Dora Mbanya and Dr Judith Shang and the entire Laboratory and clinical personnel of the University of Yaounde Teaching Hospital and Shamka Foundation for all their support during the entire period of this study. We are also grateful to all Cameroonians who volunteered to participate in this study.

\section{GRANT/FUNDING SUPPORT}

This study was support by grant number V29-181-22 from WHO-UNAIDS HIV Vaccine Initiative to the Principal Author (G. Alemnji).

\section{REFERENCES}

[1] Ministry of Public Health. Preliminary report of the 2004 Demographic and Health Survey. Maryland-USA: Measure DHS+, 2004.

[2] Peeters, M.; Toure-Kane, C.; Nkengasong, J.N. Genetic diversity of HIV in Africa: impact on diagnosis, treatment, vaccine development and trials. AIDS, 2003, 17, 2547-2560.

[3] Simon, F.; Mauclère, P.; Roques, P.; Loussert-Ajaka, I.; MüllerTrutwin, M.C.; Saragosti, S.; Georges-Courbot, M.C.; BarréSinoussi, F.; Brun-Vézinet, F. Identification of a new human immunodeficiency virus type 1 distinct from group $\mathrm{M}$ and group $\mathrm{O}$. Nat. Med., 1998, 4(9), 1032-1037.

[4] Keele, B.F.; Van Heuverswyn, F.; Li, Y.; Bailes, E.; Takehisa, J.; Santiago, M.L.; Bibollet-Ruche, F.; Chen, Y.; Wain, L.V.; Liegeois, F.; Loul, S.; Ngole, E.M.; Bienvenue, Y.; Delaporte, E.; Brookfield, J.F.; Sharp, P.M.; Shaw, G.M.; Peeters, M.; Hahn, B.H. Chimpanzee reservoirs of pandemic and nonpandemic HIV-1. Science, 2006, 313(5786), 523-526.

[5] Sultana, F.; Anitha, D.; Venkatesh, T. Estimation of Reference Values in Liver Function Test in Health Plan Individuals of an Urban South Indian Population. Ind. J. Clin. Biochem., 2004, 19(2), 72-79.

[6] Cheesbrough, M. Ed. Reference Ranges for Qualitative Tests. In District Laboratory Practice in Tropical countries. Cheesbrough M, Ed. Cambridge University Press. Cambridge, 2004, pp. 27-29.

[7] Kratz, A.; Lewandrowski, K.B.; Siegel, A.J.; Chun, K.Y.; Flood, J.G.; Van Cott, E.M.; Lee-Lewandrowski, E. Effect of marathon running on marathon running and hematologic, biochemical and cardiac marker. Am. J. Clin. Pathol., 2002, 118(6), 56-863.

[8] El-Hazmi, M.A.; Al-Faleh, F.Z.; Al-Mofleh, I.A.; Warsy, A.S.; AlAskah, A.K. Establishment of normal "Reference" ranges for biochemical parameters for healthy Saudi Arabs. Trop. Geogr. Med., 1982, 34(4), 323-332.

[9] Brigden, M.L.; Heathcote, J.C. Problems in interpreting laboratory tests: what do unexpected results mean? Postgrad. Med., 2000, 107(7), 145-6, 151-152.

[10] Alimonti, A.; Bocca, B.; Mannella, E.; Petrucci, F.; Zennara, F.; Cotichini, R.; D'ippolito, C.; Agresti, A.; Caimi, S.; Forte, G. Assessment of reference values for selected elements in a healthy urban population. Ann. Ist. Super. Sanita, 2005, 41, 181-187.

[11] El-Hazmi, M.A.; Al-Faleh, F.Z.; Al-Mofleh, I.A.; Warszy, A.S.; Al-Askah, A.K. Establishment of normal "Reference" ranges for haematological parameters for healthy Saudi Arabs. Trop. Geogr. Med., 1982, 34(4), 333-339.

[12] Friedewald, W.T.; Levy, R.I.; Fredrickson, D.S. Estimation of the concentration of low density lipoprotein cholesterol in plasma, without use of the preparative ultracentrifuge. J. Clin. Chem., 1972, $18,499-502$.

[13] Knight, E.M.; Spurlock, B.G.; Edwards, C.H.; Johnson, A.A.; Oyemade, U.J.; Cole, O.J.; West, W.L.; Manning, M.; James, H.; Laryea, H. Biochemical profile of African American women during third trimesters of pregnancy and at delivery. J. Nutr., 1994, 124(6Suppl), 943S-953S.

[14] Kayitenkore, K.; Ketter, N.; Stoll, L.; Shutes, E.; Allen, S.; Stevens, G.; Kambili, C.; Dally, L.; Karita, E. Clinical laboratory reference ranges in adults at project San Francisco in Kigali/Rwanda. Third Forum of the African AIDS Vaccine Program (AAVP), Yaounde, Cameroon, 2005.

[15] Kibaya, R. Normal laboratory reference range values from East Africa. Third Forum of the African AIDS Vaccine Program $(A A V P)$, Yaounde, Cameroon, 2005.

[16] Otokwula, A.A.E.; Isichei, U.P.; Das, S.C. Establishment of a local biochemical reference range: Jos university teaching hospital experience. Highland Med. Res. J., 2002, 1(1), 17-20.

[17] Hale, W.E.; Stewart, R.B.; Marks, R.G. Haematological and biochemical laboratory values in an ambulatory elderly population: an analysis of the effects of age, sex and drugs. Age Ageing, 1983, 12, 275-284.

[18] Mazzaccara, C.; Labruna, G.; Cito, G.; Scarfò, M.; De Felice, M.; Pastore, L.; Sacchetti, L. Age-related reference intervals of the main biochemical and hematological parameters in $\mathrm{C} 57 \mathrm{BL} / 6 \mathrm{~J}$, 129SV/EV and C3H/HeJ mouse strains. PLoS One, 2008, 3(11), e3772.

[19] Moniz, C.F.; Nicolaides, K.H.; Bamforth, F.J.; Rodeck, C.H. Normal reference ranges for biochemical substances relating to renal, hepatic and bone function in fetal and maternal plasma through pregnancy. J. Clin. Path., 1985, 38, 468-472. 
[20] Nilsson, S.E.; Evrin, P.E.; Tryding, N.; Berg, S.; McClearn, G.; Johansson, B. Biochemical values in persons older than 82 years of age: report from a population-based study of twins. Scand. J. Clin. Lab Invest., 2003, 63(1), 1-13.

[21] Ngogang, J.; Titanji, V.P.K. The concentration of apolipoproteins and lipoprotein cholesterol in sera of normal and hypertensive African subjects from Yaounde, Cameroon. East Afr. Med. J, 1985, 62(7), 446-451.

[22] Raisonnier, A.; Tagny, G.P.; Kamso-Tchakounte, J.; Sile, H.J.; Muna, W. Apolipoprotein and lipid composition of low-density lipoproteins and high-density lipoproteins in Cameroonians: a very low atherogenic risk. Ann. Univ. Sci. Santé., 1988, 5(3-4), 755-763.
[23] Gouado, I.; Mbiapo, T.; Chouanguep, F. Profil lipidique d'une population rurale de l'ouest du Cameroun. Sante., 1996, 6, 397400.

[24] Ndomou, M.; Ngogang, J.; Kenne, M. Concentration des lipides et apolipoproteines sériques dans une population urbaine saine du Nord-Cameroun : variation selon l'âge et sexe. Sante, 1999, 169172.

[25] Zilva, J.; Pannail, P.T.; Mayne, P.O. Clinical Chemistry in Diagnosis and treatment, $5^{\text {th }}$ ed. ELBS \& Edward Arnold, publishers, Uk, 1991.

[26] Danwa, C.; Atchou, G.; Nkam, M.; Mbuagbaw.; Mougnoutou, R.; Nkouanfack, C.; Mbanya, D.; Agbor, A.G.; Lohoue, J.; Ngogang, J.Y. Effect of antiretroviral therapy on lipid metabolism in HIV/AIDS subjects in Cameroon. J. Med. Sci., 2005, 5(2), 78-82.

(c) Alemnji et al.; Licensee Bentham Open.

This is an open access article licensed under the terms of the Creative Commons Attribution Non-Commercial License (http://creativecommons.org/licenses/ by-nc/3.0/) which permits unrestricted, non-commercial use, distribution and reproduction in any medium, provided the work is properly cited. 